\title{
Pengaruh Diabetes Self Management Education (DSME) terhadap Self Management pada Pasien Diabetes Mellitus
}

\author{
Trina Kurniawati', Titih Huriah ${ }^{2}$ Yanuar Primanda $^{3}$ \\ ${ }^{1}$ Universitas Muhammadiyah Pekajangan Pekalongan, email: trinakurniawati@yahoo.co.id \\ 2 Universitas Muhammadiyah Yogyakarta \\ ${ }^{3}$ Universitas Muhammadiyah Yogyakarta
}

\begin{abstract}
Abstrak
Edukasi kepada pasien Diabetes Mellitus (DM) yang dapat memperbaiki hasil klinis adalah Diabetes Self Management Education (DSME). DSME merupakan salah satu metode yang dapat memfasilitasi pengetahuan dan keterampilan. Penelitian ini bertujuan untuk mengetahui pengaruh Diabetes Self Management Education terhadap Self Management pada pasien DM. Penelitian ini menggunakan metode penelitian quasi experimental dengan control group pre test- post test design. Teknik pengambilan sampel menggunakan teknik Simple random sampling dengan jumlah sampel sebanyak 46 orang yang terbagi menjadi 23 orang pada kelompok intervensi mendapatkan DSME sebanyak 4 sesi dalam satu bulan dan 23 orang pada kelompok kontrol mendapatkan edukasi dari Program PERSADIA. Instrumen yang digunakan menggunakan kuesioner. Analisis statistik menggunakan Wilcoxon dan Mann Whitney test. Hasil penelitian menunjukkan bahwa $\mathrm{P}$ value uji Wilcoxon test sebesar 0,000 pada kelompok intervensi, $\mathrm{P}$ value uji Mann Whitney test adalah 0,000 pada variabel self management. Berdasarkan hasil uji statistik didapatkan $p<0,05$ yang menunjukkan bahwa terdapat perbedaan nilai self management antara kelompok intervensi dengan kelompok kontrol secara signifikan. Kesimpulan penelitian ini adalah DSME dapat meningkatkan self management pada pasien DM. Disarankan petugas kesehatan dapat memberikan DSME untuk meningkatkan self management pasien diabetes dan menggunakan DSME sebagai program promosi kesehatan.
\end{abstract}

Kata kunci: Diabetes Mellitus; DSME;Self Management

The Influnce of Diabetes Self Management Education (DSME) to the Self Management on the Diabetes Patient

\begin{abstract}
Education to patients Diabetes Mellitus (DM) who can improve clinical outcomes is Diabetes Self Management Education (DSME). DSME is one method that can facilitate knowledge and skills. The purpose of this research is to determine the effect of Diabetes Self Management Education (DSME) to Self Management on the diabetes patients. This study is used the quasi experimental research method with control group pre test post test design. The sampling technique used Simple random sampling with a samples of 46 people and it is devided 23 people in the intervention group get DSME as much as 4 sessions in one month and 23 people in the control group get education programe at PERSADIA. The instrument used was questionnaire. Statistical analysis used Wilcoxon and Mann Whitney test. The results showed that P value of Wilcoxon test was 0.000 in the intervention group, $P$ test value of Mann Whitney test was 0.000 in self management variable. Based on statistical test results obtained $p<0.05$ which indicates that there are differences in self-management value between the intervention group and the control group significantly. The conclusions of this research is DSME can improve self-management on the patients with diabetes. It is recommended that health workers can provide DSME to improve self-management in diabetic patients and use DSME as a health promotion program.
\end{abstract}

Keywords : Diabetes Mellitus, DSME, Self Management 
Pendahuluan

Diabetes Mellitus (DM) merupakan salah satu penyakit kronis yang paling banyak dialami oleh penduduk di dunia. Penyakit DM menempati urutan ke-4 penyebab kematian di negara berkembang (Sicree et.al., 2009). Meningkatnya jumlah penderita DM setiap tahun, khususnya DM tipe 2 dipengaruhi oleh perubahan sikap hidup yang kurang terkontrol. PERKENI (2011) menyatakan terdapat 4 pilar utama dalam penatalaksanaan DM tipe 2, yaitu edukasi, terapi gizi medis, latihan jasmani, dan intervensi farmakologis. Salah satu aspek yang memegang peranan penting dalam penatalaksanaan DM adalah edukasi. Edukasi yang dapat diberikan pada pasien DM adalah Diabetes Self Management Education(DSME).

DSME merupakan komponen penting yang dapat memberikan kemampuan pada individu untuk melakukan tindakan manajemen diri dalam mengelola penyakit diabetes mellitus dalam mengatasi masalah kesehatan yang mengancam status kesehatannya (Soegondo, 2013).

Diabetes Self Management Education merupakan suatu proses yang memfasilitasi pengetahuan, ketrampilan dan kemampuan perawatan mandiri (self care behavior) yang sangat dibutuhkan oleh penderita diabetes (Funell, 2010). Perawatan mandiri yang baik dan benar pada pasien DM sangat diperlukan dalam upaya pencegahan dini melalui promotif, preventif, kuratif dan rehabilitatif. Proses edukasi bertujuan mempengaruhi penderita untuk mengikuti rekomendasi terapi yang dianjurkan oleh tenaga kesehatan dalam menerapkan tiga hal, yaitu : pengetahuan, sikap, dan tindakan dalam perawatan penyakit diabetes mellitus (Soegondo, 2013).

Perawat sebagai seorang educator dan counselor bagi pasien, menurut Orem di dalam Tomey dan Alligood (2006) dapat memberikan bantuan kepada pasien dalam bentuk supportive-educative dengan memberikan pendidikan dengan tujuan agar pasien mampu melakukan perawatan secara mandiri sehingga tercapai kemampuan untuk mempertahankan kesehatan dan kesejahteraannya. Hal inilah yang mendorong peneliti untuk melakukan penelitian tentang pengaruh Diabetes Self Management Education terhadap Self Management pada pasien Diabetes Mellitus.

\section{Metode}

Penelitian ini menggunakan desain quasy experiment (eksperimen semu) dengan rancangan pre and post test control group design. Sampel dalam penelitian ini sebanyak 46 orang yang dibagi menjadi 2 kelompok yaitu 23 orang kelompok intervensi dan 23 orang kelompok kontrol dengan menggunakan metode Probability sampling melalui Simple random sampling yaitu setiap elemen diseleksi secara acak, nama ditulis pada secarik kertas, diletakkan dikotak, diaduk dan diambil secara acak setelah semuanya terkumpul untuk mencegah terjadinya bias seleksi. Kelompok intervensi diberikan Diabetes Self Management Education (DSME) setiap minggu selama 1 bulan, sedangkan kelompok kontrol diberikan Pendidikan Kesehatan dari Program PERSADIA. Kelompok intervensi dan kelompok kontrol diminta untuk tidak mengikuti pendidikan kesehatan tentang Diabetes Mellitus selain di PERSADIA agar dapat mencegah terjadinya bias confounding pada hasil penelitian.

Penelitian dilakukan pada bulan Januari 2018 di PERSADIA Batang. Variabel independen dalam penelitian ini adalah Diabetes Self Management Education (DSME), sedangkan variabel dependen adalah Self Management yang diukur dengan menggunakan kuesioner untuk Self Management. Intervensi Diabetes Self Management Education (DSME) diberikan dengan menggunakan buku panduan yang dibentuk menjadi modul yang telah mengacu pada pedoman. Data yang didapatkan berupa skor self management, analisis data yang digunakan adalah uji wilcoxon dan mann whitney test. 
Hasil Penelitian

1. Pengaruh Self Management antara sebelum (pre) dan sesudah (post) pemberian Diabetes Self Management Education (DSME) pada Kelompok Intervensi dan kontrol

Tabel 1. Hasil Self Management antara sebelum (pre) dan sesudah (post) pemberian DSME pada kelompok intervensi dan kontrol $(\mathrm{N}=46)$

\begin{tabular}{|c|c|c|c|c|c|}
\hline \multicolumn{2}{|l|}{ Variabel } & \multirow{3}{*}{$\mathbf{n}$} & \multicolumn{3}{|c|}{ Min- } \\
\hline Self & & & $\begin{array}{c}\text { Mean } \\
\pm \text { SD }\end{array}$ & Maks & $\mathrm{P}$ \\
\hline \multicolumn{5}{|l|}{ Management } & \\
\hline Kelompok & Sebelum & 23 & 28 & $16,00-$ & 0,000 \\
\hline Intervensi & & & $\begin{array}{c}47 \pm 6 \\
65\end{array}$ & 38,00 & \\
\hline \multirow{4}{*}{$\begin{array}{c}\text { Kelompok } \\
\text { Kontrol }\end{array}$} & Sesudah & 23 & $\begin{array}{c}36 \\
60 \pm 1 \\
75\end{array}$ & $\begin{array}{c}34,00- \\
39,00\end{array}$ & \\
\hline & & & 27,43 & & \multirow{3}{*}{0,000} \\
\hline & Sebelum & 23 & $\begin{array}{c} \pm \\
6,570\end{array}$ & $\begin{array}{c}16,00- \\
38,00\end{array}$ & \\
\hline & Sesudah & 23 & $\begin{array}{c}31,26 \\
\pm \\
5,585\end{array}$ & $\begin{array}{c}19,00- \\
39,00\end{array}$ & \\
\hline
\end{tabular}

Berdasarkan table 1. dapat diketahui bahwa rata-rata self manajemen pada responden sesudah diberikan Diabetes Self Management Education (DSME) meningkat yaitu 36,60 . Rata-rata self manajemen pada responden sesudah diberikan standar care (kelompok kontrol) mengalami peningkatan yaitu 31,26. Berdasarkan uji wilcoxon test, didapatkan nilai p-value sebesar 0,000 . Terlihat bahwa p-value $0,000<\alpha(0,05)$, ini menunjukkan bahwa ada peningkatan Self Management antara sebelum (pre) dan sesudah (post) pemberian Diabetes Self Management Education (DSME) pada kelompok intervensi.

2. Perbedaan Pengaruh Self Management antara kelompok intervensi dan kelompok kontrol
Tabel 2. Perbedaan Pengaruh Self

Management antara kelompok intervensi dan kelompok kontrol

\begin{tabular}{cccccc}
\hline Variabel & & n & $\begin{array}{c}\text { Mean } \pm \\
\text { SD }\end{array}$ & $\begin{array}{c}\text { Min- } \\
\text { Maks }\end{array}$ & P \\
& & & & & \\
\hline Self & Intervensi & 23 & $36,78 \pm$ & $34,00-$ & 0,000 \\
management & & & 2,15 & 43,00 & \\
& & & & & \\
& & & $31,26 \pm$ & $19,00-$ & \\
& Kontrol & 23 & 5,58 & 39,00 &
\end{tabular}

Berdasarkan Tabel 2 terlihat bahwa rata-rata self manajemen setelah diberikan Diabetes Self Management Education (DSME) sebesar 36, 78 pada kelompok intervensi, sedangkan rata-rata self manajemen setelah diberikan standar care pada kelompok kontrol sebesar 31,26. Berdasarkan uji Mann- Whitney test, didapatkan nilai p-value sebesar 0,000 . nilai $p$-value tersebut lebih kecil dari $\alpha$ $(0,05)$ yang menunjukkan bahwa ada perbedaan pengaruh antara kelompok intervensi dan kelompok kontrol yaitu intervensi pada kelompok intervensi lebih berpengaruh dibandingkan kelompok kontrol.

\section{Pembahasan}

Pemberian DSME pada kelompok intervensi dapat meningkatkan pengetahuan dan keterampilan pasien dalam melakukan perawatan mandiri, sehingga indikator/tanda dan gejala resiko terjadinya DM yang muncul sebelum pemberian DSME berkurang lebih banyak dari pada kelompok kontrol (Funnell, 2008).

Pasien pada kelompok kontrol telah mengetahui konsep dasar DM secara umum dan perawatan mandiri yang harus dilakukan, namun rata-rata pasien pada kelompok kontrol menyatakan tidak melakukan perawatan mandiri secara rutin dan komprehensif, seperti perawatan kaki, pengaturan nutrisi, dan jenis olah raga yang dianjurkan.

Peningkatan self management yang terjadi pada kelompok kontrol, walaupun lebih rendah dari pada kelompok perlakuan 
disebabkan karena kelompok kontrol juga mendapatkan pendidikan kesehatan, yaitu diberikan informasi tentang kesehatan akan tetapi tidak dilakukan evaluasi. Walaupun edukasi tanpa dilakukan evaluasi setelahnya, namun tetap saja di dalamnya terdapat informasi mengenai penyakit dan pengelolaan penyakitnya. Sehingga hal tersebut akan berkonstribusi dalam peningkatan self management pasien pada kelompok kontrol. Karena sesuai dengan hasil penelitian Falvo di dalam Atak (2010) yang menyatakan bahwa pemberian pendidikan kesehatan dapat meningkatkan self efficacy seseorang.

Hasil penelitian ini bersesuaian dengan hasil penelitian Funnel (2010) dengan metode randomized control trial menunjukkan intervensi pemberdayaan pasien dengan menggunakan DSME akan menghasilkan peningkatan secara signifikan terhadap pengontrolan hemoglobin glikosilasi, self management, kemampuan pengelolaan stress, penyediaan dukungan, kemampuan mengambil keputusan yang tepat dalam pengelolaan diabetes.

Hal tersebut diperkuat oleh Perkumpulan Endokrinologi Indonesia (2011) yang menyatakan bahwa ada empat pilar penanganan utama pada pasien DM tipe 2, yaitu edukasi, terapi nutrisi medis, latihan jasmani, dan intervensi farmakologis. Edukasi memegang peranan yang sangat penting dalam penatalaksanaan DM karena pemberian edukasi kepada pasien dapat merubah perilaku pasien dalam melakukan perawatan mandiri DM.

Edukasi dapat diberikan melalui suatu promosi kesehatan. Promosi kesehatan merupakan proses pemberdayaan atau memandirikan masyarakat agar dapat memelihara dan meningkatkan kesehatannya (Ottawa Charter, 1986 dalam Maulana, 2009). Proses pemberdayaan atau memandirikan masyarakat tidak hanya terbatas pada pemberian informasi (seperti pendidikan kesehatan) tetapi juga upaya untuk merubah perilaku dan sikap seseorang, sehingga promosi kesehatan dapat meningkatkan kemampuan kognitif, afektif, dan psikomotor seseorang (Maulana, 2009).

Durasi waktu untuk perubahan perilaku tidak ditentukan secara jelas karena kemampuan setiap individu dalam menerima dan merespon stimulus berbeda. Perilaku yang tidak didasari oleh pengetahuan dan kesadaran maka tidak akan berlangsung lama (Roger, dalam Notoatmodjo, 2003). (Hosland et.al. 1953 dalam Notoatmodjo, 2003) menyatakan bahwa proses perubahan perilaku sama dengan proses belajar. Proses perubahan perilaku menggambarkan proses belajar pada individu yang terdiri dari stimulus (rangsang), proses dan efek tindakan (perilaku).

Stimulus yang diberikan dapat diterima atau ditolak. Stimulus yang ditolak akan berhenti dan stimulus yang diterima berarti ada perhatian dari individu terhadap stimulus. Stimulus yang diterima akan diolah sehingga timbul reaksi kesediaan untuk bertindak atau bersikap. Stimulus pada akhirnya akan mempunyai efek tindakan atau perubahan perilaku dengan bantuan dukungan baik fasilitas maupun lingkungan (Notoatmodjo, 2003).

DSME merupakan salah satu bentuk edukasi yang efektif diberikan kepada pasien DM karena pemberian DSME dapat meningkatkan pengetahuan, sikap, dan perilaku pasien dalam melakukan perawatan mandiri. DSME bertujuan untuk mendukung pengambilan keputusan, perawatan diri, pemecahan masalah, dan kolaborasi aktif dengan tim kesehatan, sehingga dapat meningkatkan hasil klinis, status kesehatan, dan kualitas hidup (Funnell et.al., 2008).

Pemberian DSME dapat merubah perilaku pasien melalui informasi yang diberikan kepada pasien. Pemberian informasi kepada pasien merupakan suatu stimulus yang dapat meningkatkan pengetahuan, sehingga menimbulkan kesadaran untuk berperilaku sesuai dengan yang diharapkan. Pasien DM memiliki kemampuan dan respon yang berbeda 
terhadap stimulus yang diberikan, sehingga perilaku dan kemampuan pasien dalam melakukan perawatan mandiri juga berbeda. Pemberian DSME dapat menghasilkan berbagai outcome, yaitu hasil jangka pendek, hasil jangka menengah, dan hasil jangka panjang (Norris et.al., 2002).

Kelebihan pemberian DSME dapat memberikan hasil yang positif, baik hasil jangka pendek, jangka menengah, maupun jangka panjang. Hasil jangka pendek meliputi kontrol glikemik (hemoglobin terglikosilasi dan gula darah), kontrol fisik (berat badan, kadar lipid, luka pada kaki, tekanan darah, mikroalbuminuria, retinopati), modifikasi gaya hidup (aktivitas fisik, diet, kebiasaan merokok), dan kontrol status mental (depresi dan ansietas).

Hasil jangka menengah meliputi peningkatan pengetahuan, keterampilan (memecahkan masalah, kontrol gula darah secara mandiri, dan penggunaan obatobatan), status psikologis (kepercayaan diri, perilaku, koping), dan pemanfaatan fasilitas pelayanan kesehatan (rutin kontrol). Hasil jangka panjang meliputi pencegahan komplikasi makrovaskular (penyakit vaskuler perifer, penyakit jantung coroner, penyakit serebrovaskuler), pencegahan komplikasi mikrovaskuler (penurunan penglihatan, neuropati perifer, penyakit ginjal, penyakit gigi dan mulut, ulkus diabetik, dan amputasi), penurunan angka kematian, peningkatan kualitas hidup, dan perbaikan sosial ekonomi (Norris et.al., 2002).

Berdasarkan hasil penelitian yang dilakukan oleh Sidani \& Fan (2009), pasien DM yang menerima DSME dapat mengalami perbaikan kontrol metabolik, perbaikan kualitas hidup, dan mengurangi komplikasi. Hasil penelitian yang dilakukan oleh Rondhianto (2011) juga menyatakan bahwa DSME terbukti memiliki pengaruh yang positif terhadap peningkatan kepercayaan diri dan perubahan perilaku perawatan diri pasien DM.

Dengan adanya pemberian DSME pada pasien DM dalam penelitian ini, pasien memperoleh informasi terkait perawatan mandiri DM. Pengetahuan, keterampilan, dan status psikologis pasien mengalami peningkatan, sehingga pasien mulai melakukan perawatan mandiri terhadap penyakitnya.

Komponen DSME yang diajarkan selama pemberian DSME kepada pasien DM dalam penelitian ini adalah pengetahuan dasar tentang DM, pengaturan nutrisi/diet, olah raga atau latihan fisik, perawatan kaki, terapi farmakologis dan monitoring kadar gula darah.

Selama proses pemberian DSME, peneliti mengeksplorasi pengetahuan yang telah dimiliki pasien dan perawatan yang telah dilakukan. Peneliti juga mengeksplorasi perasaan dan keluhan yang dirasakan pasien. Komponen-komponen DSME yang diajarkan kepada pasien dapat meningkatkan pengetahuan dan keterampilan pasien sekaligus memperbaiki perawatan yang dilakukan pasien yang kurang benar.

Komponen-komponen DSME yang telah diajarkan kepada pasien dapat meningkatkan pengetahuan dan keterampilan perawatan mandiri pasien. Kemampuan individu untuk melakukan perawatan diri (Self Care) dipengaruhi oleh usia, status perkembangan, pengalaman hidup, orientasi sosial budaya, kesehatan, dan sumber daya yang tersedia. Perawatan diri dilakukan karena adanya masalah kesehatan atau penyakit dengan tujuan mencegah penyakit dan meningkatkan kesehatan (Asmadi, 2008).

\section{Simpulan}

Terdapat hasil peningkatan nilai ratarata Self Management setelah diberikan Diabetes Self Management Education (DSME) pada kelompok intervensi dan terdapat perbedaan pengaruh antara kelompok intervensi yang mendapatkan intervensi DSME dan kelompok kontrol yang mendapatkan intervensi standar edukasi dari PERSADIA.

DSME dapat dijadikan sebagai suatu program promosi kesehatan untuk meningkatkan kemampuan perawatan 
mandiri pasien DM tipe 2. DSME dapat dijadikan suatu SOP, sumber referensi, atau sumber acuan dalam penanganan pasien DM baik dalam lingkup klinik maupun komunitas. Masyarakat dan responden diharapkan dapat menerapkan ilmu yang telah diperoleh melalui perawatan mandiri yang benar sehingga diharapkan masyarakat juga ikut serta membantu melakukan perawatan mandiri dan mengurangi komplikasi yang terjadi pada pasien akibat penyakit DM.

\section{Daftar Pustaka}

1. Sicree, R.,Shaw, J., \& Zimmet P. 2009. The Global Burden. IDF Diabetes Atlas 4th Ed.

2. Perkumpulan Endokrinologi Indonesia. 2011. Konsensus Pengelolaan dan Pencegahan Diabetes Mellitus Tipe 2 di Indonesia. Jakarta: PB. PERKENI.

3. Soegondo, S., Soewondo, P., dan Subekti, I., 2013. Penatalaksanaan Diabetes Melitus Terpadu. Edisi ke 2. Jakarta: Balai Penerbit FKUI.

4. Rondhianto. 2011. Pengaruh Diabetes Self Management Education dalam Discharge Planning terhadap Self Efficacy dan Self Care Behaviour Pasien Diabetes Mellitus Tipe 2. [tesis]. Surabaya: Program Studi Magister Keperawatan Fakultas Keperawatan Universitas Airlangga.

5. Tomey A.M. dan Alligood M. R. (2006). Nursing Theorists and Their Work. 6th ed. USA: Mosby Elsevier.

6. Nursalam. 2008. Konsep dan Penerapan Metodologi Penelitian Ilmu Keperawatan: Pedoman Skripsi, Tesis, dan Instrumen Penelitian Keperawatan. Jakarta: Salemba Medika.

7. Sastroasmoro \& Ismael. 2011. Dasardasar Metodologi Penelitian Klinis. Edisi-4 Jakarta: Bina Rupa Aksara.

8. Hastono, S. P. (2001). Analisis Data. Universitas Indonesia. Jakarta.

9. Dahlan, S. (2011). Statistik untuk Kedokteran dan Kesehatan. Salemba Medika. Jakarta.
10. Potter \& Perry. (2005). Buku Ajar Fundamental Keperawatan Konsep, Proses, dan Praktik. Edisi 4 volume 1.EGC.Jakarta

11. Irnawati, K., Nursam, M., (2014). Pengaruh Diabetes Self Management Education Terhadap Self Care Behavior pada pasien Diabetes Mellitus. STIKES Wira Medika PPNI. Bali.

12. Jazilah, Paulus Wijono, Toto Sudargo. (2003). Hubungan Tingkat Pengetahuan, Sikap dan Prektik (PSP) Penderita Diabetes Mellitus Mengenai Pengelolaan Diabetes Mellitus dengan Kendali Kadar Glukosa Darah. Universitas Gajah Mada. Yogyakarta.

13. Rahmadiliyani, N. (2008). Hubungan antara Pengetahuan tentang Penyakit dan Komplikasi pada Penderita Diabetes Mellitus dengan Tindakan Mengontrol Kadar Gula Darah. Sukoharjo: Wilayah Kerja Puskesmas I Gatak.

14. Funnell, M. M., et.al. 2008. National Standards for Diabetes SelfManagement Education. Diabetes Care Volume 31 Supplement 1: p. S87-S94.

15. Norris, S.L., Lau, J., Smith, S.J., Schmid, C.H., \& Engelgau, M.M. Self Management Education for Adults With Type 2 Diabetes A meta-analysis of the effect on glycemic control. Diabetes Care, 25:1159-1171. 2002.

16. Norris SL, Nichols PJ, Caspersen CJ, Glasgow RE, Engelgau MM, Jack L, et al. Increasing diabetes self-management education in community settings. A systematic review. Am J Prev Med., 222(4 Suppl):39-66. [PMID: 11985934] 2002.

17. Notoatmodjo, S. 2003. Pendidikan dan Perilaku Kesehatan. Jakarta : Rineka Cipta

18. Notoatmodjo, S. 2007. Promosi Kesehatan dan Ilmu Perilaku. Cetakan Pertama. Jakarta: Rineka Cipta.

19. Rahmawati. 2015. Pengaruh program Diabetes Self Management Education terhadap manajemen diri pada penderita DM tipe 2. (Tesis). Banda Aceh: 
Jurnal Ilmiah Kesehatan (JIK) Vol XII, No II, September 2019 ISSN 1978-3167, E-ISSN 2580-135X

Program Studi Magister Keperawatan Universitas Syiah Kuala.

20. Yuanita. (2013). Pengaruh Diabetes Self

Management Education (DSME)

terhadap resiko terjadinya ulkus diabetik pada pasien rawat jalan dengan diabetes mellitus (DM) tipe 2 di RSD dr. Soebandi Jember. Skripsi. Universitas Jember. Jember. 